\title{
Trouble in the Heartland: Challenges Confronting Rural Jails
}

Rick Ruddell

Law Foundation of Saskatchewan Chair in Police Studies

Department of Justice Studies

University of Regina

3737 Wascana Parkway

Regina, Saskatchewan, Canada, S4S 0A2

Phone: (306) 337-8541

Email: rick.ruddell@uregina.ca

G. Larry Mays

Regents Professor Emeritus

Department of Criminal Justice

New Mexico State University

Phone: (505) 792-4771

Email: glmays@nmsu.edu

${ }^{a}$ Contact author - Rick Ruddell: rick.ruddell@uregina.ca; 0103063378541

\begin{abstract}
There has been very little scholarship on the roles and functions of rural jails in the United States. This study examines some of the key challenges facing these small correctional institutions, using data from two national surveys, focus groups of jail administrators, and the results from a survey of Texas jail administrators. These studies solicited information about the operational challenges and changing offender populations in small and rural jails. In order to better respond to these changing characteristics, a number of policy options for rural jails are considered, including: regionalization, transferring the operations of local jails to state departments of corrections, increasing alternatives to incarceration, expanding local capacity, abiding by standards or becoming accredited, and privatizing local corrections. The merits of these different solutions are examined.
\end{abstract}

Keywords: Rural Jails, Local Corrections, Small Jail Operations. 


\section{Introduction}

Criminal justice researchers have generally focused on the issues of crime and justice in urban areas. Yet, there is growing interest in understanding the nature of crime in rural communities and how officials have responded to these offenses (Deller and Deller, 2010; Falcone, Wells, and Weisheit, 2002; Lee and Thomas, 2010; Payne, Berg, and Sun, 2005). Some of this increasing attention may result from Federal Bureau of Investigation (FBI) data that show high rates of crime in some rural areas. In 2010, for instance, average levels of violent crime in counties of fewer than 10,000 residents was greater than larger non-metropolitan counties, or metropolitan counties of 25,000 to 99,999 residents (FBI, 2011). As a result, overlooking the crimes that occur in rural areas, and the responses of their justice systems, seems short-sighted, especially given that some 51 million Americans lived in non-metropolitan counties in 2010, and these populations have increased by 2.2 million since 2000 (U.S. Department of Agriculture, 2011: 5).

Responses to rural crime are organized at the county level and jails are often the center for the operations of most rural justice systems (Applegate and Sitren, 2008). This study focuses on these small correctional institutions and some of the operational obstacles created by the stand-alone nature of these facilities, the economic and political environments in which they operate, and the characteristics of their populations. Many of the problems associated with jail operations, such as reliance upon local funding, the difficulty of recruiting and retaining professional staff, the political role of the sheriff, and managing special needs offenders were identified almost a century ago (Fishman, 1923, Robinson, 1915) and have defied simplistic solutions or attempts at reform (Ruddell, 2010).

American jails were modeled on British justice systems that required that jails be located in every county. Given Britain's relatively small geographical size and dense population, this was an effective approach when transportation of offenders was a time consuming and potentially dangerous proposition. This model was imported with the Colonists and jails were established in most American counties and parishes, although there was some regional variation in the forms of these fledging correctional facilities. In most jurisdictions, jails became the hub of the local justice system, typically housing the sheriff's office and residence, and they were often located adjacent to the local courthouse or were constructed as an annex to the courthouse. In most states, elected sheriffs oversee the operations of the jail, and Kellar (2005: 160) notes that most sheriffs focus upon law enforcement and that, "the jail function of the sheriff's office has little political sex appeal"...and, "the sheriff is under no perceived 
political obligation to maintain a quality jail operation as long as the jail does not get out of control."

Many rural jails are very small and in 1982 there were 355 American jails of ten or fewer beds (Mays and Thompson, 1988). In 1982 the National Sheriffs' Association reported that there were 2,821 jails of fewer than 100 beds (Mays and Thompson, 1988), but this number had decreased to 1,706 by 2005 (Sabol and Minton, 2008). The disappearance of these jails can be attributed to a number of reasons, including facilities that closed, regionalization, and smaller facilities that expanded (Kerle, 2003). As Ruddell and Mays (2006) noted, small jails are being forced to either expand or expire.

Rural jail administrators face all of the challenges of large urban jails (see Stinchcomb and McCampbell, 2007) but they are further disadvantaged by their location in counties that can draw from a relatively small tax base, and as a result, they suffer from a corresponding lack of funding. Furthermore, like their urban counterparts, rural communities have been impacted by the recent economic downturn and county administrators in these places are attempting to reduce their jail populations and cutting operational costs (National Association of Counties, 2011; PEW Charitable Trusts, 2010). The following pages describe the challenges confronting rural jails using information from four recent studies of small facilities, and we present a number of policy alternatives that might lead to safer and more effective jail operations.

\section{Rural Jails: Small Facilities, Substantial Challenges}

Despite the fact that jails hold about one-third of all U.S. correctional populations and they admitted about 13 million persons in 2010 (Minton, 2011), there has been comparatively little scholarship about jail operations, and the study of these facilities has been relegated to the sidelines of the penological literature. In addition, while American jails range in size from fewer than ten beds to the Los Angeles jail system that held an average 14,671 inmates from January to March, 2011 (California Corrections Standards Authority, 2011), when research is conducted, it generally focuses upon larger facilities. Furthermore, officials from the National Institute of Corrections (NIC) have focused their attention upon improving service delivery in these larger facilities with the establishment of the Large Jails Network. To be fair, however, a relatively small number of the largest jails hold most inmates, and Minton (2011: 6) reports that jails with an average daily population of 1,000 or more held one-half $(50.1 \%)$ of all jail inmates in 2010 . All of the jails that have a daily average 
population of fewer than 100 beds, by contrast, accounted for only $8 \%$ of all jail inmates in 2010 (Minton, 2011).

Scholars have typically defined whether jails are "large" or "small" by their rated capacity (usually expressed in beds) or average daily population. Mays and Thompson (1988) define small as ten beds or fewer while Kerle used the descriptor small to classify facilities of fewer than 100 beds (Kerle, 2004). Ruddell and Mays (2006; 2007) also used the classification of fewer than 100 beds to describe small, while the NIC defines small jails as having fewer than 150 beds (see LIS Incorporated, 2001).

Small jails are most often located in rural areas, although even the term "rural" can be defined in a number of ways (Weisheit and Donnermeyer, 2000). Hart, Larson and Lishner (2005: 1149) observe that, "the term suggests pastoral landscapes, unique demographic structures and settlement patterns, isolation, low population density, extractive economic activities, and distinctive sociocultural milieus." Given that there are 2,052 non-metropolitan counties in the United States (U.S. Department of Agriculture, 2003) what constitutes rural in one region of the nation might look decidedly different in another place. A review of the literature reveals that academic disciplines define rural differently (e.g., in agricultural, criminological, educational and health studies). Since 2003, however, the U.S. Census has defined rural areas and non-metropolitan counties using the population as well as proximity to urban areas (U.S. Department of Agriculture, 2003). Non-metropolitan counties are, by contrast, defined by the FBI (2011) using the population size (e.g., fewer than 10,000 residents, from 10,000 to 24,999 residents and larger than 25,000 residents).

In this study the terms "rural" and "small" are used interchangeably and small facilities are defined as having an average daily population of less than 100 beds. We acknowledge that large jails can sometimes be located in rural counties or that facilities of less than 100 beds could exist in some metropolitan areas, and this classification is a limitation of this study. Applegate and Sitren (2008: 258), for instance, note that, "jails in most rural counties...ranged from one to 548 inmates, and nearly one quarter $(23 \%)$ could house more than 100 inmates."

A literature review revealed few recent studies that focused solely on rural jail operations. Three of these contributions were chapters in an edited book on rural criminal justice systems and a common theme was that smaller jails face considerable operational challenges (see Cronk, 1982). Kerle (1982) identifies under-funding and personnel issues as key problems in smaller facilities. Miller (1982) surveyed jail administrators and reports that the main problems in facilities of 25 or fewer beds 
centered upon the physical plant (such as the age of the facility and space requirements), operations (e.g., safety, security or classification) and a lack of rehabilitative opportunities. Taking a more critical perspective, Katsampes (1982) argues that many of the problems confronting smaller facilities are the result of managers failing to plan, develop written policies, create alternatives to incarceration, or abide by jail standards. Katsampes (1982) also observes that officials in standalone rural jails tend to be isolated from contemporary correctional practices.

Results of subsequent studies of small jail operations produced similar results. Kimme (1985) observes that many officials fail to take advantage of resources such as the NIC, do not abide by jail standards nor do they seek accreditation with agencies such as the American Correctional Association (ACA). Mays and Thompson (1988) also focused upon the operational challenges of jails with ten or fewer beds and observe that many operations were hamstrung by their physical plants, and this placed inmates at higher risk of violence, as well as increased the likelihood of interactions between male and female inmates, as well as juveniles and adults.

Texas county jail administrators in Kellar's (2001) study report that the most pressing problems confronting smaller facilities are related to human resource management (e.g., officer retention), a lack of rehabilitative programming and delivering constitutionally mandated medical care. In addition, the size of a facility was thought to shape management practices, officer salaries, access to rehabilitative opportunities, staffing arrangements and security measures. Kellar (2001: 99) observes that, "Neither large jails nor small jails are inherently better than the other; they are merely different institutions with different goals, structures and traditions. Standards should not be compromised for the sake of jail size."

A survey of officials from jails of fewer than 150 beds reveals that the operations of many were constrained by their physical plants - either shortages in space or crowding - and that few were constructed using the direct supervision jail design (LIS Incorporated, 2001). The likelihood of an inmate participating in any rehabilitative endeavor varied by location and LIS Incorporated (2001: 2) also reports that, "Fewer than half (38\%) of the jails offer any type of industry, work detail, or job preparation programs. Substance abuse counseling/treatment is available in $62 \%$ of the responding jails, and educational programs are offered in 67\%." Similar to the results reported in earlier research, these investigators also report recruiting and retaining staff was a significant concern.

Two recent studies of jails of fewer than 100 beds reveal that the operational challenges confronting small jails identified by the investigators in the 1980s are still 
present. Ruddell and Mays (2006) report that jail operations were often hampered by economic constraints and that these small facilities were disappearing. A follow-up study finds that the operations of rural jails were shaped by changing inmate populations and that special needs inmates (e.g., persons with mental illness) placed a significant demand on staff time and resources (Ruddell and Mays, 2007).

Applegate and Sitren (2008) used data from the 1999 Census of Jails to examine the differences between jail operations in nine different classifications of rural and urban counties. These investigators found that facilities in rural counties tended to operate less efficiently — with higher staff to inmate ratios than jails in urban counties - and fewer of these staff were Black or Latino. There was, however, a higher proportion of women working in rural jails, and this finding was consistent with the results of Kellar's (2001) Texas study. In terms of rehabilitative opportunities, Applegate and Sitren (2008: 264) found that inmates in rural jails had fewer opportunities to participate in inmate work programs, educational courses, or treatment interventions such as life skills, parenting or employment.

\section{Operational Challenges Confronting Rural Jails}

Altogether, a review of prior research shows that there are a number of persistent operational problems that small jails have faced for generations. In order to increase our understanding of the key issues confronting rural jail administrators, we compare the results from four studies, and these results are presented in Table 1.

The first study, conducted by LIS Incorporated (2001) for the NIC, surveyed 500 officials from jails with fewer than 150 beds and received responses from 251 officials, representing facilities with an average rated capacity that ranged from 36 to 193 beds (the average jail reported an average capacity of 101 inmates). In total, 44 states were represented in this research. In addition to asking respondents about a number of facility-related questions (e.g., the age of the facility, space limitations, and the methods of inmate supervision), these officials were asked about the potential problem areas facing their jails.

Kellar's (2001) survey of Texas jail administrators is also included in the analysis, and although this study lacks a national focus, it is important for our understanding of small jails as most of the 145 respondents $(60.7 \%)$ were from facilities of fewer than 50 beds, and facilities of fewer than 250 beds accounted for $84.8 \%$ of the sample. This study replicated earlier research conducted by del Carmen, Witt, Hume, and Ritter (1990), who identified that the top five issues of concern to jail administrators 
at that time were: overcrowding, budget, staff-related, medical and the physical plant (as reported in Kellar, 2001: 96).

Ruddell and Mays (2006) report the results from a 2005 survey of 361 jail administrators from facilities of fewer than 100 beds. Of that number, 213 administrators responded, and these administrators come from a cross-section of the United States, including responses from 43 states. These facilities had an average capacity of 43.1 beds, and they hold an average daily population of 39.9 inmates in a building that is approximately four decades old, and many of these jails have been in operation for over a century. These antiquated facilities are not only more expensive to operate, but their design does not accommodate the direct supervision of inmates, thus increasing the risks of disorderly or criminal conduct (Wener, 2006).

The fourth study was conducted using focus groups of 45 sheriffs and jail administrators who were brought together to identify the key issues facing American jails (Stinchcomb and McCampbell, 2007). These practitioners from jail operations of varying sizes were involved in this study, and included participants-primarily elected sheriffs and jail administrators - from both small (fewer than 50 beds) and large operations (over 2,000 beds). The focus groups were conducted in 2007, and a smaller group $(\mathrm{n}=15)$ participated in a follow-up meeting to clarify and expand upon the results. In addition to the participants, a number of individuals from stakeholder organizations, such as the American Correctional Association, American Jail Association, National Institute of Corrections, and the National Sheriffs Association, acted as observers.

Regardless of the methods used, the respondents who participated, or the year in which these studies took place, the practitioners in these four studies report nearly identical problems facing their jail operations. Funding and workforce concerns are a priority for administrators in jails of all sizes, and the research that included inmate health as an option was also identified as a key issue. Moreover, respondents from all of the studies described at least one limitation of their physical plants, such as crowding, space limitations, or inadequate technological capability. What is remarkable about these findings are the similarities to the key issues confronting small jails in research and commentary about jails reported decades earlier (Abbott, 1916; Fishman, 1923; Katsampes, 1982; Kerle, 1982; Kimme, 1985; Kinsella, 1933; Robinson, 1915). This further reinforces our observations about the long-term, entrenched nature of the problems associated with jail operations. 


\section{Table 1 Practitioner Perceptions of the Top Challenges Facing Jails}

\begin{tabular}{|c|c|c|c|}
\hline $\begin{array}{l}\text { Kellar }(2001) \\
\text { Sample: Texas } \\
(\mathrm{n}=145)\end{array}$ & $\begin{array}{l}\text { LIS (2001) } \\
\text { Sample: National } \\
(\mathrm{n}=251)\end{array}$ & $\begin{array}{l}\text { Ruddell \& Mays } \\
\text { (2006) } \\
\text { Sample: National } \\
(\mathrm{n}=213)\end{array}$ & $\begin{array}{l}\text { Stinchcomb \& } \\
\text { McCampbell (2007) } \\
\text { Sample: National (n } \\
=45)\end{array}$ \\
\hline Medical costs & $\begin{array}{l}\text { Lack of qualified } \\
\text { candidates for hiring }\end{array}$ & Funding & $\begin{array}{l}\text { Workforce } \\
\text { (recruitment, hiring, } \\
\text { retention) }\end{array}$ \\
\hline Budget/funding & $\begin{array}{l}\text { Inadequate funding for } \\
\text { personnel and } \\
\text { operations }\end{array}$ & $\begin{array}{l}\text { Programs for } \\
\text { offenders }\end{array}$ & $\begin{array}{l}\text { Medical care } \\
\text { (pharmaceuticals, } \\
\text { staff, infectious } \\
\text { diseases) }\end{array}$ \\
\hline Staff training & Staff turnover & $\begin{array}{l}\text { Recruit and retain } \\
\text { jail officers }\end{array}$ & $\begin{array}{l}\text { Mental health } \\
\text { (care, training, cost) }\end{array}$ \\
\hline Overtime & $\begin{array}{l}\text { Contraband/Contraband } \\
\text { passage }\end{array}$ & Jail overcrowding & $\begin{array}{l}\text { Technology } \\
\text { (management } \\
\text { information systems, } \\
\text { fingerprint systems, } \\
\text { enhanced security } \\
\text { and communications) }\end{array}$ \\
\hline Crowding & $\begin{array}{l}\text { Inadequate funding for } \\
\text { physical plant }\end{array}$ & Jail violence & Funding \\
\hline Mental Health & $\begin{array}{l}\text { Difficulty managing } \\
\text { special inmates }\end{array}$ & Jail suicide & $\begin{array}{l}\text { Administrative issues } \\
\text { (accountability, long } \\
\text { range planning, } \\
\text { mission change, } \\
\text { oversight) }\end{array}$ \\
\hline
\end{tabular}

As Stinchcomb and McCampbell (2007: 35-36) observe about managers from smaller jails:

“this group's priorities reflected the limited resources which are available

to smaller, rural jails and the need to decrease the isolation of such

facilities. Such jails need assistance with planning and developing appropriate inmate medical services, and with leveraging community health and mental health services, which are often stretched beyond capacity." 
Apart from crowding, some of the key issues that jail administrators identify in these four studies are a consequence of the inmate population. In the LIS Incorporated (2001: A-2) study, for instance, the foremost problem area identified by over three-fifths of the respondents $(60.3 \%)$ was managing "special inmates." In order to better understand how jail populations contribute to the challenges of managing these rural operations, we take a closer look at the characteristics of these jail inmates.

\section{Special Needs Inmates: Prevalence and Conduct}

The Ruddell and Mays (2007) survey solicited information about the presence of special needs inmates in the respondent's jails, including persons with severe mental illness, habitual misdemeanor offenders (also called "frequent fliers"), gang-involved inmates, persons with serious illnesses, elderly inmates, and long-term inmates (inmates incarcerated for longer than one year). Jails have always had to respond to the needs of these inmates and each of these groups pose special challenges for the operations of correctional facilities, either for their involvement in disruptive behavior, their threats to safety and security, or the inordinate resources required for their care. Participants were asked to estimate the size of these groups in their jails, and the risks that they posed to the orderly operations of their facilities. Table 2 shows the average prevalence of these five groups in the 213 facilities, and these range from gang-involved inmates, which accounted for $3.7 \%$ of the population, to habitual misdemeanor offenders (persons with over 20 arrests), who represented almost one-third (31.5\%) of the population of these facilities.

\section{Table 2 Special Needs Jail Populations and Their Conduct in Rural Jails}

\begin{tabular}{|l|c|c|}
\hline \multicolumn{1}{|c|}{ Special Needs Group } & $\begin{array}{c}\text { Prevalence } \\
\text { Average (s.d.) }\end{array}$ & $\begin{array}{c}\text { Disruption } \\
\text { Index }\end{array}$ \\
\hline Persons with Severe Mental Illness & $8.6 \%(16.1)$ & 4.4 \\
\hline Habitual Misdemeanor Offenders & $31.5 \%(29.8)$ & 2.1 \\
\hline Gang-Involved Inmates & $3.7 \%(8.5)$ & 2.3 \\
\hline Seriously Ill & $4.4 \%(9.5)$ & ---- \\
\hline Long-Term Inmates (over 1 year) & $13.9 \%(20.3)$ & 1.9 \\
\hline
\end{tabular}

1. The disruption index is the mean of disruptive or criminal behaviors (self harm or suicidal behavior, rates of victimization, involvement in assaults on inmates or officers, involvement in other criminal conduct, escapes/attempts, and disruptive behavior). Highest possible group value is 7.0. 
Participants were also asked to rate how unruly these inmates were based on a list of disruptive or criminal behaviors within the facility (e.g., engaging in assaults or causing a disturbance). Respondents were given seven different examples of disruptive behavior, and the values were summed for each group; the most disruptive group had a maximum possible ranking of seven. Not surprisingly, persons with mental illness were identified as the most disruptive group, and they are commonly encountered in local corrections. James and Glaze (2006: 1), for example, report that nationwide $64 \%$ of jail inmates have some sort of mental health problem, with $21 \%$ having a recent history or symptoms. The definitions that are used for mental health in different studies might influence the results, and in the James and Glaze (2006: 3) research, a recent history included being diagnosed by a mental health professional, having an overnight hospital stay, using prescribed medications, or having professional mental health therapy. In this study, by contrast, the descriptor "severe mental health problem" was used, suggesting that only the inmates with the most serious mental health problems were counted.

Habitual misdemeanor offenders have always posed special challenges for local corrections. Consistent with the extant literature (Berg and DeLisi, 2005; Chandler Ford, 2005), these inmates were defined as having 20 or more jail admissions in the previous five years. Bass (2005) reports that habitual misdemeanor offenders are often caught in a cycle of arrests for minor offenses, short-term detention or incarceration, release and unsuccessful community reentry. The annual number of admissions of these offenders tends to increase over time (Chandler Ford, 2005), as well as the seriousness of their offenses (Bass, 2005). Table 2 shows that these inmates are not as disruptive as other inmates, but they do consume an inordinate amount of county resources and a Florida sheriff recently expressed frustration that five of these repeat offenders had accumulated almost 900 arrests among them (WINK News, 2011). The results from this study show that this group represents a sizable proportion of the rural jail population and would represent a significant cost to local corrections.

Gangs are typically considered to be an urban problem, yet research demonstrates that these groups also represent a threat to law enforcement in rural communities (Weisheit and Wells, 2004). Egley, Howell and Moore (2010: 1) report that the proliferation of gangs and gang members increased in rural counties between 2002 and 2008. Studies of gang involvement in jails show that they represent from $13 \%$ to $16 \%$ of jail populations in the United States (Ruddell, Decker, and Egley, 2006; Wells, Minor, Angel, Carter and Cox, 2002). The results in this study show that they are less prevalent in rural jails (3.7\%) although respondents ranked them as the second most disruptive group. 
One significant challenge for all correctional administrators is managing the cost of inmate medical care. National-level studies conducted by the Bureau of Justice Statistics show that $36.9 \%$ of jail inmates have a current medical problem, and that 13.4\% have been injured since their admission to the jail (Maruschak, 2006: 1).

Costs of providing medical care to jail inmates have increased significantly over the past two decades and in some jurisdictions financial considerations determine when an inmate will be released (Ruddell and Tomita, 2008). Anecdotal accounts, for example, suggest that some sheriffs and jail administrators release sentenced jail inmates prior to their presumed discharge date if their health care costs become excessive.

Having a greater proportion of seriously ill inmates is one factor that contributes to high mortality rates within small jails. Respondents in this study indicated that about $4.4 \%$ of inmates had serious health problems. While less than reported in the Maruschak (2006) study, a relatively small number of these inmates can result in significant health care costs. Figure 1, for instance, shows the average mortality rates from 2002 and 2007, and shows that jails of fewer than 50 beds have the highest death rates (Noonan, 2011: 5). The primary reason for these elevated mortality rates is the high suicide rate within these facilities, and deaths due to illness, are the second leading cause of death in small jails.

Figure 1: Mortality in U.S. Jails, by Facility Size, 2002 to 2007.

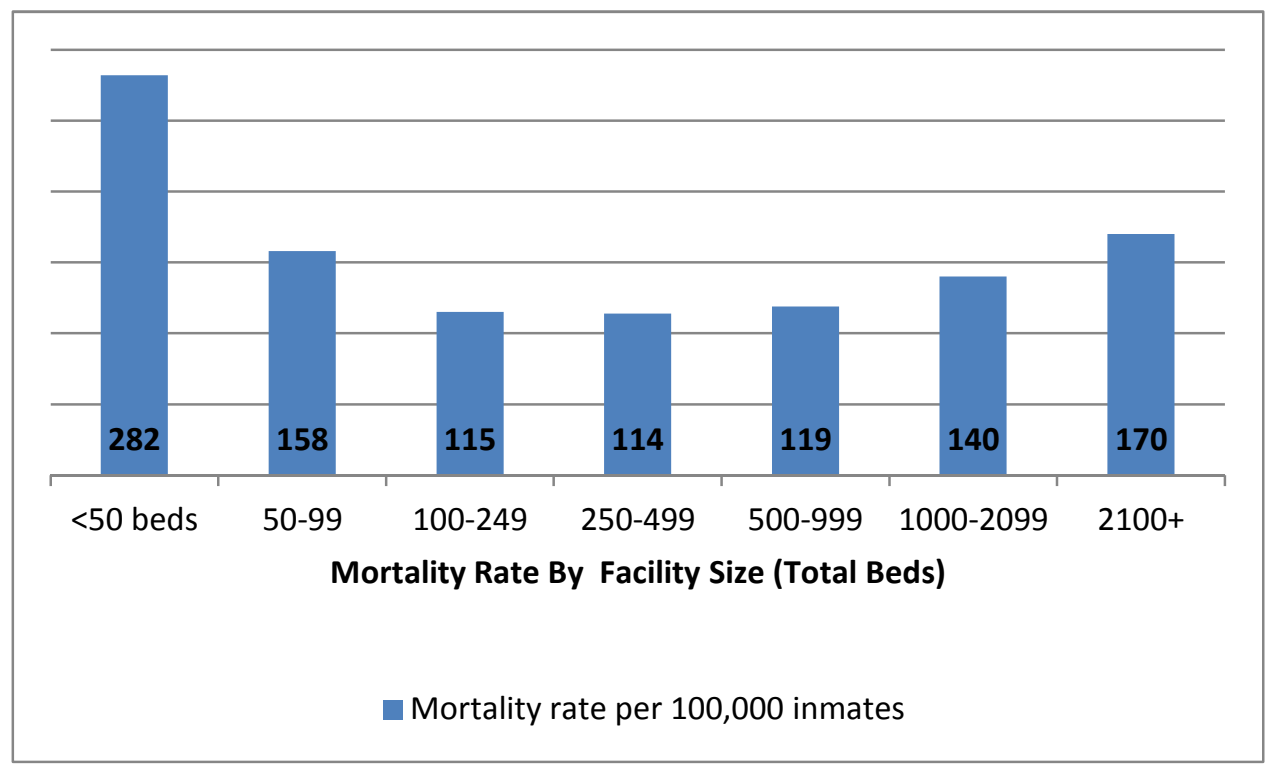


Jails were historically intended to house inmates for relatively short periods of time and few small jails offer comprehensive rehabilitative opportunities (Applegate and Sitren, 2008; Kellar, 2001; LIS Incorporated, 2001). This is a long-standing tradition in local corrections as inmates confined to lengthy periods of jail incarceration are often idle (Fishman, 1923). It was therefore surprising to find that an average of $13.9 \%$ of jail inmates had been incarcerated for longer than a year. This estimate is in sharp contrast to the results of a national-level study that finds that $4.8 \%$ of inmates have been in jail for more than one year, and $1.4 \%$ have been held for more than three years (James, 2004).

There are a number of possible reasons for this finding. It is plausible that lengthy sentences are more common in rural areas—what Feld (1991) calls justice by geography. Longer case processing times in rural courts might result in lengthier periods of pretrial detention, and it is possible that rural jail inmates serve a greater proportion of their sentences than their urban counterparts before release. Another possible reason for these lengthy periods of confinement is that some inmates are detained for several months (or longer) and then are sentenced to a term of jail incarceration. Furthermore, some inmates, especially in the South, are awaiting transfer to crowded state prisons (Harrison and Beck, 2006). West, Sabol, and Greenman (2010: 36), for example, report that $11.2 \%$ of all state prisoners in the South are held in local facilities, while none of the other three regions (North, East, or West) hold over $2 \%$ of state prisoners in jails.

Altogether, the five special needs populations reported above pose significant challenges in terms of their likelihood of disrupting jail operations, reducing safety and security, as well as increasing operational costs. Given the current economic recession, jail administrators and their funding agencies must develop creative ways to manage these risks and costs. The following section highlights a number of potential policy responses that might enable rural jails to better respond to the challenges already identified.

\section{Rural Jail Policy Alternatives}

Ultimately, rural jail administrators, like their urban counterparts, have very little control over the types or numbers of persons who are arrested and sentenced (King Davis, Applegate, Otto, Surrette, and McCarthy, 2004). Moreover jail funding is also external to the organization, and there is increasing competition for scarce taxpayer dollars with other county services (National Association of Counties, 2011). These difficulties are exacerbated by the fact that there is little public sympathy for jail inmates or political incentives to provide quality care (Kellar, 2005). Working 
toward more cost-effective and professionally operated jails, however, can result in improvements in the services delivered to rural communities, and make their treatment consistent with that received by inmates in metropolitan areas. Ruddell and Mays (2006) identified a number of policy options that have been adopted in some rural jurisdictions and the following section updates and expands those alternatives.

\section{Regionalization}

Regionalization occurs when a number of jurisdictions combine their operations into a single jail. There are a number of benefits associated with regionalization, although the primary rationale is financial, as these arrangements enable the justice system to take advantage of economies of scale that reduce operational costs. As these regional operations are typically much larger than the facilities they replace, a greater number of rehabilitative interventions can be offered, and their size enables these facilities to be more responsive to the changing needs, populations and priorities of the justice system.

While most local sheriffs may be reluctant to relinquish their influence by participating in these arrangements, a number of states, such as Ohio, Virginia and West Virginia, have introduced financial incentives for counties that participate in these arrangements (Dennis, 1998). These incentives must overcome a number of obstacles including differences in management philosophies and styles, increased operational costs (e.g., transportation from surrounding counties; see Edelman and Mayer, 1997), location disagreements, and the absence of legal authority to undertake these arrangements (NIC, 1992: 1). A key question is whether the benefits of regionalization outweigh the losses to the local community.

One of the most significant barriers to regionalization is that the jail is often the cornerstone of a rural justice system, and that these facilities often include the sheriff's administrative offices. As a result, losing these facilities results in a loss of local autonomy, and once closed, it is unlikely that the jail will be replaced. A secondary consideration in communities where the population is declining is that residents are often very sensitive to eliminating county services and the jobs associated with them. Interestingly, however, the Corrections Center of Northwest Ohio (2011) reports that in the recent development of a regional jail, none of the counties wanted the facility constructed in their town.

All of the barriers to regionalization are political, and county politicians, sheriffs and other stakeholders must support these initiatives. These groups must weigh the costs and benefits of regionalization, especially during tough economic times. While 
reluctant to lose local jobs, county leaders are beginning to acknowledge the economic inefficiencies of small operations and the potential for litigation for failing to deliver constitutionally appropriate services. One of the survey items in the Ruddell and Mays (2006) research asked participants whether they had been involved in discussions about regionalization, and while about one-third of them had indicated such discussions, fewer than $10 \%$ indicated that regionalization was a possibility. Thus, it seems unlikely that more jurisdictions will become involved in these arrangements.

\section{State-Operated Jails}

Six states-Alaska, Connecticut, Delaware, Hawaii, Rhode Island and Vermonthave integrated jail-prison systems. In these jurisdictions the costs of pre-trial detention and short-term incarceration are borne by the state rather than local governments. There are a number of advantages with these arrangements, as this process enables detention and short-term incarceration to be consolidated, resulting in fewer but larger facilities that can be managed centrally. Moreover, as jail operations fall under the auspices of the state's Department of Corrections, there is increased standardization. Perhaps most importantly, this arrangement reduces political interference and some of the long-standing negative traditions of local corrections such as nepotism and cronyism (Ruddell, 2010).

Transferring the operations of local corrections to a higher level of government is a practice that is consistent with what occurs in most common-law nations. One of the primary advantages for local governments is that jail costs are distributed among the entire state population. Yet Mays and Thompson (1988) also observe that stateoperated jails may have the unintended consequence of increasing the incarceration rate. In some communities, for example, prosecutors may not advocate for incarceration when the local jail is overcrowded, a practice that Edelman and Mayer (1997) observe in their study of rural Iowa jails. Consequently, increasing the capacity for incarceration combined with a shift of responsibility to the state might result in an increased use of detention and short-term incarceration.

\section{Alternatives to Incarceration}

Many jurisdictions have implemented alternatives to incarceration programs. Minton (2011: 12) reports that on June 30, 2010 there were 60,632 jail inmates supervised in the community in weekender programs, electronic monitoring, home detention, day reporting, community service, pretrial supervision, and other work or treatment programs. It is important to note, however, that the proportion of jail 
inmates participating in these community-based alternatives has actually decreased from $9.5 \%$ in 2000 to $7.5 \%$ in 2010 (Minton, 2011).

Alternatives to incarceration illustrate the ingenuity of local justice systems to respond to overcrowding, although in some jails, liberal release-on-recognizance policies for nonviolent offenders realistically can relieve some tension on crowding. As a result, the current budget crisis may motivate sheriffs and county administrators to develop community-based programs that act as alternatives to holding arrestees or minor offenders in jail (National Association of Counties, 2009; Piquero, 2010). The PEW Charitable Trusts (2010: 4) reports, for instance, that:

"Alternatives to incarceration have saved small Tompkins County, New York, an estimated $\$ 1.89$ million in jail costs over the last five years. These programs include a day reporting center-a place where defendants and offenders check-in daily and are supervised while remaining in the community - and a treatment court where offenders participate in drug and alcohol treatment in lieu of incarceration."

Community-based alternatives to incarceration might not be feasible in all rural counties. Although the options listed above are cheaper than incarcerating an arrestee or offender, most require additional community infrastructure supports and supervision. If the local probation departments are unable or unwilling to manage this additional burden, sheriffs' offices may take the responsibility for community supervision. Yet, sheriffs are increasingly asked to do "more with less" and they may have few resources to supervise even relatively small numbers of jail inmates residing in the community.

One of the most controversial alternatives to incarceration is reducing the time served for sentenced jail inmates. Ruddell and Mays (2006) report that a jail inmate sentenced to a year in the local jail might serve approximately nine months of that time before being released, with the balance being an early release (or "good time" credits - which is a sentence reduction for good behavior). In some jurisdictions, offenders serve even less of their sentence and del Barco (2010) reports that residents of the Los Angeles County jail receive two days good time credit for every day they serve in jail. Although these early release programs are primarily intended for nonviolent and first-time offenders, there is concern that these early releases undermine faith in the local justice system.

\section{Expanding Capacity in Local Jails}


In order to finance their jail operations a number of entrepreneurial sheriffs or administrators expand jail capacity in order to house inmates from other counties, as well as state and federal prisoners. Perhaps the most lucrative contacts for these jails are with the federal government. Local jails have held prisoners for the federal government on a fee-for-service basis for over a century (see Fishman, 1923; Kinsella, 1933). Moreover, the expansion in the detention of illegal immigrants after the $9 / 11$ attacks has created a lucrative market for some jails with unused bed space. On June 30, 2010, about 3.5\% of all U.S. jail inmates were held for the U.S. Immigration and Customs Enforcement (Minton, 2011: 9).

Semple (2011) reports that about 260 jails currently hold immigration detainees for the federal government, and that in New Jersey correctional facilities are paid about $\$ 105$ per day to hold these detainees. In most cases, the operational cost of adding an additional inmate to the jail's count is a fraction of that amount. This results in a profit for the jail, and these funds are used to reduce operational costs. Some rural jails have become dependent upon these funds. The Etowah County Detention Center, located in rural Alabama, for example, has a rated capacity of 900 inmates, and on average 400 of these beds are used for immigration detainees (Etowah County Sheriff's Office, 2010).

Operating jails as revenue-generating enterprises may lead to a number of unintended consequences, including mistreating inmates. Podkul (2011) reports for instance, that local correctional officials sometimes hold immigration detainees for an unconstitutionally long period in order to maximize profits. As a result of these practices, and other cost-cutting measures, such as rationing health care, some jails could find themselves at increased risk of litigation (Schlanger, 2003). A third unintended consequence of expanding capacity to hold inmates for other jurisdictions is that some sheriffs have actually overbuilt, and they cannot fill their empty beds. Benjamin (2011) reports that a California jail lost its contract to hold department of corrections prisoners, and the facility is now empty; this represents a burden for county taxpayers (Ellis, 2008; PEW Charitable Trusts, 2010). Given these unanticipated consequences, King, Mauer, and Huling (2003) question whether expanding the capacity of correctional facilities in rural communities is a sustainable proposition.

Harrison and Beck (2006) report that almost 10\% of the persons held in local jails on June 30, 2005 were state prison inmates awaiting a transfer. In Louisiana and Tennessee, for example, inmates can serve much of their prison sentences in a local jail (Ruddell, 2005). Placing these prison inmates in local jails may be a short-sighted practice because of the lack of rehabilitative opportunities in these facilities 
(Applegate and Sitren, 2008; LIS Incorporated, 2001) so taxpayers might not always get a good return on the investment they have made in jail incarceration.

\section{Privatization}

Some counties have contracted out jail services to corporations. This transfers the responsibility of housing inmates to corporations and there are a number of financial advantages to privatization. First, the county can purchase these services on a feefor-service basis and are no longer responsible for long-term facility maintenance, paying for unused capacity, or employee benefits and pensions. Second, private operators can generally provide correctional services at a reduced cost, often because they pay lower salaries and benefits than their public counterparts. Moreover large correctional corporations can often contain costs through bulk purchasing and maximizing the use of technology.

Stephan (2001: 6) reports that the number of inmates in privately-operated jails increased throughout the 1990s and by 199947 jails, holding a total of 16,656 inmates, were run by private operators. One of the limitations of fully understanding the privatization of local corrections, however, is a dearth of current information about the number of inmates being held in privately-operated facilities, where these facilities are located, and which corporations are managing these facilities. In addition, there is a lack of research about the safety and efficacy of privately-operated detention facilities and jails.

One of the problems associated with correctional privatization is that profits often result from reducing officers' salaries (these account for approximately three-fourths of operational costs). Consequently, we return to the problem identified in the four studies reported above: the difficulty in recruiting and retaining professional correctional officers who will make working in a rural jail their long-term career (Kellar, 2001; LIS Incorporated, 2001; Ruddell and Mays, 2006; Stinchcomb and McCampbell, 2007).

Large private corrections corporations such as the Corrections Corporation of America or the GEO Group hold a relatively small proportion of their total inmate population in local corrections, and it is unlikely that they will play much of a role in managing the entire operations of rural jails, given their small size and therefore limited profitability. It is more likely that private corporations will partner with smaller jail operations to provide support services, such as inmate food services, transportation (e.g., to court or between facilities), and health care services. 


\section{Standards, Litigation, and Accreditation}

Kimme (1985) is critical of jail administrators who did not take advantage of services offered by the NIC or who fail to abide by jail standards. The NIC, for instance, offers technical assistance and a range of consulting services to jails free-ofcharge. Moreover, the NIC provides online instruction and video conference opportunities in a wide range of corrections related issues, including facility management. For stand-alone facilities that are not part of a larger network, the NIC enables administrators to benefit from the experiences of others, thus reducing the isolation of staff working in these facilities. The LIS Incorporated (2001) study reports that only $43 \%$ of their respondents had utilized the services of the NIC, suggesting that it remains an untapped resource for most small jail administrators.

Prior studies of small jails reveal that few abide by jail standards, and that many do not have written policies and procedures (Katsampes, 1982). More recently, 98.8\% of the respondents in the LIS Incorporated (2001) research reported that daily operations were governed by written policies and procedures. Written policies may be mandated by states that have implemented jail standards. Martin (2007) notes, for instance, that 32 states had established some type of formal jail standards, and Arizona sheriffs voluntarily comply with non-binding minimum guidelines.

Ruddell (2010) notes that jail standards provide a benchmark for jail operations, but that some sheriffs and administrators have opposed these initiatives, fearing that written standards would expose them to a greater likelihood of inmate litigation. Martin (2007: 1) observes, by contrast, that jails that abide by standards are safer, more humane, and experience fewer inmate-related problems such as assaults, the importation of contraband and suicidal behavior. Moreover, the lack of formal standards or written policies and procedures does not make an agency immune to litigation. The American Correctional Association (2011b), for instance, has reported that in many of the states with formal jail standards there are no formal inspections or audits.

One possible outcome of not complying with professional correctional practices is the increased likelihood of litigation. In one of the most comprehensive studies of jail litigation, Schlanger (2003) reports the top three sources of individual lawsuits in jails are medical care, use of force, and personal injury. In terms of class action lawsuits, by contrast, the three main reasons are medical care, search policies and crowding. It is important to note that medical care is the number one issue for both individual and class action lawsuits, as it is also a key challenge identified by the participants in the Kellar (2001) and Stinchcomb and McCampbell (2007) studies. Ruddell and Tomita 
(2008) identify the obstacles of jails complying with constitutionally appropriate care, and this compliance is often difficult for jail administrators in cash-strapped rural counties.

Altogether, inmate lawsuits have resulted in hundreds of millions of dollars in damages paid to individuals, and class action litigation has resulted in jail officials being required to make substantial operational changes. In order to reduce the likelihood of litigation, a number of local jails have pursed accreditation with the American Correctional Association (ACA) or the National Commission on Correctional Health Care. Accreditation indicates compliance with a set of national standards and the ACA (2011b) has highlighted a number of advantages to becoming accredited including: improving staff training, program development, contributing to a safer environment, and reduced liability insurance. In addition, some governments might require that their prisoners be held in accredited facilities. Achieving accreditation, however, is a costly and time consuming proposition and Gibbons and de B. Katzenbach (2006) report that less than 5\% of jails are accredited. As a result of the costs involved, it is unlikely that many small jails can afford this option.

\section{Discussion}

Jail operations, like other elements of the justice system, are under increasing scrutiny from agency funders, community stakeholders as well as the media. Along with scrutiny there is the increased possibility of inmate litigation if jail administrators attempt to contain costs by decreasing staffing, increasing crowding, or rationing health care. Unlike prisons that are part of larger networks, most jails are stand-alone facilities that are sensitive to the local political environment and they can draw upon few external resources. Not only are resources limited, but the public might not support increases in jail funding while other county services-to more sympathetic populations, such as youngsters in school—are being cut. Administrators and sheriffs responsible for directing the operations of small jails may be at a further disadvantage to respond to these challenges as they may be more professionally isolated than their urban counterparts (Kellar, 2001; LIS Incorporated, 2011).

A number of scholars have observed that rural jails are further burdened because the jail might be one of the few community resources, and therefore it becomes the "default" mechanism for a lack of programs in other economic, social, and health related systems: Individuals in crisis are arrested and jailed because no alternative exists (Thompson and Mays, 1991). This has certainly been the case for persons with mental illness, although the results reported above showed that a relatively small 
proportion of the entire jail population, approximately $9 \%$, suffered from severe mental illnesses. Because of the diminutive size of many of these facilities, however, inmates with special needs are mixed with the general inmate population because these jails are not large enough to have specialized units, nor are these stand-alone facilities networked, so they cannot send special needs inmates to a facility that has the capacity to respond to their needs. As a result, these inmates might be at increased risk of violence or self-harm; one possible reason for the finding that residents in small jails are six times more likely to commit suicide than inmates in larger facilities (Noonan, 2011: 5).

Almost one century ago, Robinson (1915, p. 101) called jails "a serious menace to the community" and argued that sheriffs or their administrators defied attempts at reform because the problem was "beyond their powers." Robinson advocated for the consolidation of jail operations and suggested that facilities of 500 to 1,000 beds would lead to safer conditions as well as more humane and rehabilitative treatment. In order to achieve that result, Robinson (1915: 103) observed that, "There seems, therefore, but one course, if we really wish to reform our county jails. The unit of organization must be enlarged and county management supplanted by state management." Of all of the policy alternatives, consolidated jail-prison systems seems to be the most advantageous, but also the least likely to occur.

\section{Conclusions}

There are a number of limitations in this research. It is difficult, for instance, to make conclusive comparisons between the four studies because of the different methods used to generate the results, the years examined, and the jurisdictions involved. The LIS Incorporated (2001), Kellar (2001), and Ruddell and Mays (2006) studies used survey instruments and respondents had a limited number of choices (e.g., health care was not a category in the LIS Incorporated or Ruddell and Mays studies, although was an option in the Kellar survey). The Stinchcomb and McCampbell (2007) research, by contrast, used the responses from participants in focus groups to determine the key challenges. The latter approach is more likely to result in more diverse and richer set of responses. A second limitation of this comparison is that the LIS Incorporated survey was completed in 2000, the Kellar (2001) research was conducted one year later, the Ruddell and Mays (2006) survey was undertaken in 2005, and the Stinchcomb and McCampbell (2007) focus groups were held in 2007. A third limitation is that the Kellar (2001) research examined only Texas jails, while the other three studies drew from national samples. Nevertheless, given these different methodologies it is noteworthy that the results are so consistent 
across time, facility size, and jurisdictions, and our intent is that investigators in future studies can build on these examples.

Notwithstanding the limitations reported above, our review of the operational challenges facing rural jails shows that the problems encountered by practitioners and identified by scholars for the past century are nearly identical to those confronting jail administrators today. These entrenched problems defy simplistic solutions, and instead will require a series of short- and long-term strategies. The short-term solutions are primarily operational in nature, while the long-term solutions are inherently political, and will require local governments to reevaluate the necessity of small jails. While the operations of rural law enforcement, courts, and corrections may lack the allure of their urban counterparts, we cannot overlook the fact that there are over 51 million rural residents in the United States, and they should receive just and fair treatment that is consistent with those living in the cities and suburbs.

\section{Endnotes}

${ }^{1}$ In 1877 legislation was enacted that nationalized locally-operated jails in Britain and this resulted in the closure of most of the smaller and rural facilities (Ruddell, 2010).

2 . The direct supervision design arranges inmate cells around the perimeter of the housing unit. This arrangement enables better supervision than the antiquated linear jail design (with iron cages that are arranged along long corridors and often stacked in tiers). These newer designs enable jail officers to more closely monitor and supervise the inmates and this design has been associated with increased inmate and staff safety (see Wener, 2006).

\section{References}

Abbott, E. 1916. The one hundred and one county jails in Illinois and why they ought to be abolished. Chicago, IL: Juvenile Protective Association.

American Correctional Association. 2011a. Standards and accreditation. Retrieved November 13, 2011, from http://www.aca.org/standards/benefits.asp

American Correctional Association. 2011b. Core jail standards. Retrieved November 12, 2011 from http://www.aca.org

Applegate, B. K. \& Sitren, A. H. 2008. The jail and the community: Comparing jails in rural and urban contexts. The Prison Journal, 88, 252-269. 
International Journal of Rural Criminology, Volume 1, Issue 1 (December), 2011

Bass, G. 2005. Justice and the revolving door: The Jacksonville experience in recidivism intervention. Large Jails Network, 35-38.

Benjamin, M. 2011. California county seeks inmates for empty jail. Retrieved November 12, 2011 from: http://www.fresnobee.com/2011/08/01/2485577/coalinga-seeks-inmates-forempty.html

Berg, M. T. \& DeLisi, M. 2005. Do career criminals exist in rural America? Journal of Criminal Justice, 33, 317-325.

California Corrections Standards Authority. 2011. 2011 first quarter survey result Sacramento, California: Author.

Chandler Ford, M. 2005. Frequent fliers: The high demand user in local corrections. Californian Journal of Health Promotion, 3, 61-71.

Corrections Center of Northwest Ohio. 2011. Leadership in implementing a regional jail. Retrieved November 9, 2011, from http://www.ccnoregionaljail.org/Regional\%20jail.htm

Cronk, S. D. 1982. Criminal Justice in Rural America. Washington, DC: National Institute of Justice.

del Barco, M. 2010. L.A. County jails releasing some inmates early. Retrieved November 9, 2011, from:

http://www.npr.org/templates/story/story.php?storyId=125092984

del Carmen, R. V., Witt, B. Hume, W., \& Ritter, S. 1990. Texas Jails: Law and Practice. Huntsville, TX: Sam Houston State University Press.

Deller, S. C. \& Deller, M. A. 2010. Rural crime and social capital. Growth and Change, 41, 221-275.

Dennis, J. 1998. Cooperation works: Six Ohio jurisdictions join forces to create regional jail. Corrections Today, 128-129, 140.

Edelman, M. A. \& Mayer, A. J. 1997. A Cost Analysis of County Jails by Size in Rural Iowa to Inform State Policy and Community Decisions. Retrieved November 11, 2011 from

http://www2.econ.iastate.edu/research/webpapers/NDN0050.pdf 
Egley, A., Jr., Howell, J. C. \& Moore, J. P. 2010. Highlights of the 2008 National Youth Gang Survey. Washington, DC: Office of Juvenile Justice and Delinquency Prevention.

Ellis, R. 2008. Jails: A crisis in the counties. The Daily Independent. Retrieved Nov. 11, 2011, from http://richmondregister.com/seriesnew/x155216913/JAIL-Acrisis-in-the-counties

Etowah County Sheriff's Office, 2010. Corrections. Retrieved November 8, 2011, from http://www.etowahcountysheriff.com/html/corrections.html

Falcone, D. N., Wells, L. E. \& Weisheit, R. A. 2002. The small town police department. Policing: An International Journal of Police Strategies and Management, 25, 371-384.

Federal Bureau of Investigation. 2011. Crime in the United States, 2010. Washington, DC: Author.

Feld, B. C. 1991. Justice by geography: Urban, suburban, rural variations in juvenile justice administration. The Journal of Criminal Law and Criminology, 82, $156-210$.

Fishman, J. F. 1923. Crucibles of Crime: The Shocking Story of the American Jail. Montclair, NJ: Patterson Smith.

Gibbons, J. J. \& de B. Katzenbach, N. 2006. Confronting Confinement: A Report of the Commission on Safety and Abuse in U.S. prisons. New York: Vera Institute of Justice.

Harrison, P. M. \& Beck, A. J. 2006. Prison and jail inmates at midyear 2005. Washington, DC: Bureau of Justice Statistics.

Hart, L. G., Larson, E. H., \& Lishner, D. M. 2005. Rural definitions for health policy and research. American Journal of Public Health, 95, 1149-1155.

James, D. J. 2004. Profile of jail inmates, 2002. Washington, DC: Bureau of Justice Statistics.

James, D. J. \& Glaze, L. E. 2006. Mental health problems of prison and jail inmates. Washington, DC: Bureau of Justice Statistics. 
Katsampes, P.A. 1982. A national strategy for change in rural jails. Pp. 231-248 in S.D. Cronk (ed.), Criminal justice in rural America. Washington, DC: National Institute of Justice.

Kellar, M. 2001. Texas county jails, 2001: A status report. Retrieved November 11, 2001 from: http://www.tcjs.state.tx.us/docs/Final\%20DraftTJSbu.pdf

Kellar, M. 2005. The rehabilitation dilemma in Texas county jails. The Southwest Journal of Criminal Justice, 2, 153-168.

Kerle, K. E. 1982. The rural jail: Its people, problems and solutions. Pp. 189-204 in S.D. Cronk (ed.), Criminal justice in rural America. Washington DC: National Institute of Justice.

Kerle, K. E. 1998. American Jails: Looking to the Future. Boston: ButterworthHeinemann.

Kerle, K.E. 2004. Jail evolution: Rated capacities (RC), regional jails, city jails, the growing number of women jail administrators, and new jail construction and planning new jails. American Jails, 18, 19-29.

Kimme, D. A. 1985. The nature of new small jails: Report and analysis. Longmont, CO: National Institute of Corrections.

King, R. S., Mauer, M. \& Huling, T. 2003. Big Prisons, Small Towns: Prison Economics in Rural America. Washington, DC: The Sentencing Project.

King Davis, R., Applegate, B. K., Otto, C. W., Surette, R., \& McCarthy, B. J. 2004. Roles and responsibilities: Analyzing local leaders' views on jail crowding from a systems perspective. Crime \& Delinquency, 50, 458-482.

Kinsella, N. 1933. County jails and the federal government. Journal of Criminal Law and Criminology, 24, 428-439.

Lee, M. R. \& Thomas, S. A. 2010. Civic community, population change, and violent crime in rural communities. Journal of Research in Crime and Delinquency, 47, 118-147.

LIS Incorporated. 2001. NIC Research on Small Jail Issues: Summary of Findings. Longmont, CO: National Institute of Corrections. 
Maruschak, L. M. 2006. Medical Problems of Jail Inmates. Washington, DC: Bureau of Justice Statistics.

Martin, M. D. 2007. Jail Standards and Inspection Programs. Longmont, CO: National Institute of Corrections.

Mays, G. L. \& Thompson, J. A. 1988. Mayberry revisited: The characteristics and operations of America's small jails. Justice Quarterly, 5, 421-440.

Miller, R. 1982. A needs assessment for small jails in the United States. Pp. 205-229 in S.D. Cronk (ed.), Criminal justice in rural America. Washington, DC: National Institute of Justice.

Minton, T. D. 2011. Jail Inmates at Midyear 2010 - Statistical Tables. Washington, DC: Bureau of Justice Statistics.

National Association of Counties. 2009. Jail Population Management: Elected County Officials' Guide to Pretrial Services. Washington, DC: Author.

National Association of Counties. 2011. The Recession Continues: An Economic Status Survey of Counties. Washington, DC: Author.

National Institute of Corrections. 1992. Briefing Paper: Regional Jails. Boulder, CO: National Institute of Corrections.

Payne, B. K., Berg, B. L. \& Sun, I.Y. 2005. Policing in small town America: Dogs, drunks, disorder, and dysfunction. Journal of Criminal Justice, 33, 31-41.

Piquero, A. 2010. Cost-benefit analysis for jail alternatives and jail. Retrieved November 7, 2011 from http://www.criminologycenter.fsu.edu/p/pdf/pretrial/Broward\%20Co.\%20Cos t\%20Benefit\%20Analysis\%202010.pdf

Podkul, J. 2011. Immigrant detainees languish in notorious Etowah county detention center. Retrieved November 8, 2011 from: http://www.womenscommission.org/blog/1211-immigrant-detainees-languishin-notorious-etowah-county-detention-center

Robinson, L. N. 1915. The solution of the jail problem. Journal of the American Institute of Criminal Law and Criminology, 6, 101-103.

Ruddell, R. 2005. Long-term jail populations: A national assessment. American Jails, 22-27. 
International Journal of Rural Criminology, Volume 1, Issue 1 (December), 2011

Ruddell, R. 2010. American jails: A retrospective examination. Richmond, KY: Newgate Press.

Ruddell, R., Decker, S. H., \& Egley, A. Jr. 2006. Gang interventions in jails: A national analysis. Criminal Justice Review, 31, 33-46.

Ruddell, R. \& Mays, G. L. 2006. Expand or expire: Jails in rural America. Corrections Compendium, 31, 1-5, 20-21, 27.

Ruddell, R. \& Mays, G. L. 2007. Rural jails: Problematic inmates, overcrowded cells, and cash-strapped counties. Journal of Criminal Justice, 35, 251-260.

Ruddell, R. \& Tomita, M. 2008. Issues in Correctional Health Care. Richmond, KY: Newgate.

Sabol, W. J. \& Minton, T. D. 2008. Jail Inmates at Midyear 2007. Washington, DC: Bureau of Justice Statistics.

Schlanger, M. 2003. Inmate litigation. Harvard Law Review, 116, 1557-1704.

Semple, K. 2011. Plan to Upgrade New Jersey Jail into Model for Immigrant Detention Centers. Retrieved November 9, 2011 from http://www.nytimes.com/2011/01/28/nyregion/28detain.html?pagewanted=all

Stephan, J. J. 2001. Census of Jails, 1999. Washington, DC: Bureau of Justice Statistics.

Stinchcomb, J. B. \& McCampbell, S. W. 2007. Jail leaders speak: Current and Future Challenges to Jail Administration and Operations. Naples, FL: Center for Innovative Public Policies.

Thompson, J. A. \& Mays, G.L. 1991. American Jails: Public Policy Issues. Chicago: Nelson Hall.

U.S. Department of Agriculture. 2003. Measuring Rurality: New Definitions in 2003. Retrieved November 12, 2011, from http://www.ers.usda.gov/briefing/rurality/newdefinitions/

U.S. Department of Agriculture. 2011. Rural America at a Glance: 2011 Edition. Retrieved November 8, 2011, from http://www.ers.usda.gov/Publications/EIB85/EIB85.pdf 
Weisheit, R. A. \& Donnermeyer, J. F. 2000. Change and continuity in crime in rural America. Retrieved November 11, 2011, from: http://www.ncjrs.gov/criminal_justice2000/vol_1/02g.pdf

Weisheit, R. A. \& Fuller, J. 2004. Methamphetamine in the heartland: A review and initial exploration. Journal of Crime and Justice, 27, 131-151.

Weisheit, R. A. \& Wells, L. E. 2004. Youth gangs in rural America. National Institute of Justice Journal, 251, 2-7.

Wells, J. B., Minor, K.I., Angel, E., Carter, L. \& Cox, M. 2002. A study of gangs and security threat groups in America's adult prisons and jails. Indianapolis, IN: National Major Gang Task Force.

Wener, R. 2006. Effectiveness of the direct supervision system of correctional design and management: A review of the literature. Criminal Justice and Behavior, $33,392-410$.

West, H. C., Sabol, W. J. \& Greenman, S.J. 2010. Prisoners in 2009. Washington, DC: Bureau of Justice Statistics.

WINK News. 2011. Jail's Top 5 Frequent Flyers Cost Taxpayers. Retrieved November 7, 2011, from http://www.winknews.com/Local-Florida/2011-0809/Jails-top-5-frequent-flyers-cost-taxpayers- 